\title{
Transporte de cargas especiais no modal rodoviário
}

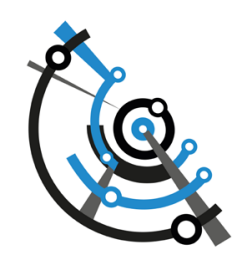

\author{
(4) Vivian Figueiredo Pereira de Almeida \\ Departamento de Pós-Graduação em Engenharia Civil, Universidade Federal Fluminense, \\ Brasil. \\ https://orcid.org/oooo-0o01-6554-1332
}

\section{Orlando Celso Longo}

Departamento de Pós-Graduação em Engenharia Civil, Universidade Federal Fluminense, Brasil.

https://orcid.org/o0oo-0002-0323-473X

Recibido: 22 de octubre de 2019. Aceptado: 2 de junio de 2020.

\section{Resumo}

A evolução do transporte de cargas especiais é indissociável do processo de avanço industrial brasileiro. Sua influência no desenvolvimento econômico do país nos traz a questão do quanto os modais de transporte, em especial o rodoviário, está preparado para receber este tipo de demanda relativamente recente. $\mathrm{O}$ desenvolvimento da infraestrutura rodoviária no Brasil é realizado principalmente por financiamento privado e através da destinação de impostos. Por sua vez, os custos da travessia de cargas especiais são impactados por taxas e condições físicas das rodovias. Neste artigo, investigou-se a percepção da qualidade das rodovias por usuários deste tipo de transporte e concluiu-se a necessidade da elaboração de políticas públicas direcionadas a recuperação e readequação da capacidade portante de pontes e viadutos, aplicação de materiais mais resistentes para o pavimento, discussão ampla da reforma tributária e destinação de valores a infraestrutura de transportes, considerando-se o espectro das cargas especiais.

Palavras-chave: Cargas Especiais. Qualidade. Percepção. Rodovias. Gestão.

\section{Transport of Special Loads on the Road Modal}

\author{
Abstract \\ The evolution of special cargo transportation is inseparable from the Brazilian indus- \\ trial advancement process. Its influence on the country's economic development raises
}


the question of how much transport modes, especially road transport, are prepared to receive this type of relatively recent demand. The development of road infrastructure in Brazil is carried out mainly through private financing and the allocation of taxes. In turn, the costs of transporting special loads are affected by fees and physical conditions of highways. This article investigates the perception of the quality of the highways attributed by users of this type of transport and concludes the need for elaboration of public policies aimed at the recovery and readjustment of the bearing capacity of bridges and viaducts, application of more resistant materials for the pavement, broad discussion of tax reform, and allocation of values to transport infrastructure, considering the spectrum of special cargo.

Key words: Special loads. Quality. Perception. Highways. Management. Palabras clave: Cargas especiales. Calidad. Percepción. Rutas. Gestión.

\section{Introdução}

O gerenciamento dos custos vem a ser fundamental em qualquer ramo de atividade, busca auxiliar nas tomadas de decisões, evitar perdas, fortalecer a sobrevivência das organizações em um mercado competitivo como o do Brasil e ser assertivo nos investimentos para o crescimento empresarial.

No Brasil, a malha rodoviária vem a ser o principal sistema logístico para possibilitar o escoamento dos produtos, serviços e fornecimento das matérias primas das organizações. Contudo o governo brasileiro pratica a cobrança de taxas e tarifas pelo uso da via nas rodovias onde possuem os pedágios, para a expansão e manutenção do sistema rodoviário de transporte.

Neste trabalho buscou-se investigar a percepção da influência da qualidade das rodovias no tempo e custo de travessias de transportes de cargas especiais. Foram identificadas as práticas de cobrança de valores de taxas e tarifas relacionadas à logística e ao financiamento rodoviário brasileiro.

Visando deslindar todo o processo de travessia desta natureza, as questões norteadoras da pesquisa foram:

a) Quais os principais custos fixos e variáveis neste tipo de transporte? (Objetivos gerais)

b) Como as rodovias brasileiras são financiadas? (Objetivos gerais)

c) Qual a percepção da influência da qualidade das rodovias na travessia de transporte de cargas especiais? (Objetivo específico e foco no resultado para o estudo, podendo haver solução ou não e sugerir políticas públicas).

Adiante, serão abordados breves conceitos e exemplos de custo fixo do transporte de cargas especiais, sendo aquele que representa os valores que devem ser pagos mesmo que o veículo esteja parado. Já o custo variável, por exemplo, flutua em função da distância, impostos, taxas etc.

No decorrer dos estudos, foram realizadas mudanças no enfoque da pesquisa. No início, foi colhido material de pesquisa da Confederação Nacional dos Transportes (CNT, 2017), cujo objetivo geral era apresentar a avaliação das características das rodovias quanto ao desempenho e segurança oferecida aos usuários em geral, considerando-se apenas três elementos: pavimentação, sinalização e geometria da via. A partir de então, elaboraram diagnósticos e classificações sobre a malha rodoviária. 
Analisando a matéria, em que pese a valia do material coletado, chegou-se a conclusão de que os critérios e pontos de reflexão não alcançavam todos os fatores de interesse dos destinatários finais da pesquisa.

Ainda assim, prosseguiam sem respostas, a exemplo dos aspectos que influenciam a definição de uma rota, a percepção do retorno da qualidade em contrapartida ao que se desembolsa por meio de tarifas do transporte, a influência de aspectos como tráfego, presença de postos policiais, bombeiros e de abastecimento de combustível, falta de estacionamento para os transportadores de cargas especiais, capacidade de pontes e viadutos e restrição de gabarito vertical e horizontal.

A pesquisa ultrapassou até mesmo a ideia inicial e acabou por retrabalhar a questão, fixando novos questionamentos, de maneira a propiciar elementos cruciais, com informações preciosas para os administradores. O resultado surpreendeu em respostas que estudos anteriores não indicavam, que são de suma importância para o tomador de decisões.

Não se quer dizer, com isso, que os métodos empregados pela Confederação Nacional dos Transportes foram errados ou que o resultado da pesquisa não seja verdadeiro. Apenas se questiona a precisão e a abrangência da pesquisa, uma vez que elas foram feitas de maneira absolutamente unilateral, ou seja, sem a oitiva do usuário, o que, certamente traria opiniões, fatos e possíveis indagações relativas ao cotidiano prático.

Consultar os usuários, conferiu a este trabalho o grau de abrangência fundamental. As respostas dadas por 20 empresas, de diferentes portes, quase sempre no mesmo sentido, certificaram as conclusões alcançadas.

O artigo foi dividido em quatro partes. Inicialmente será apresentado um breve referencial teórico sobre os custos aplicáveis nas atividades de transporte de cargas especiais, a forma de financiamento das rodovias e o que se entende por percepção de qualidade neste estudo. Em seguida, é apresentada a metodologia e delimitação do tema. A terceira parte do trabalho abarcará a análise dos fatores que influenciam o tempo e o custo das travessias de cargas especiais. Por fim, o artigo trará uma conclusão sobre a percepção da qualidade das rodovias e seus impactos no processo de transporte.

\section{Referencial teórico}

\section{Custos}

Os custos de coleta, entrega e frete, são os custos diretos das atividades do transporte de cargas especiais. O óleo diesel, por ser o principal combustível, mas não o único na atividade de transporte de cargas, usualmente é considerado nas estimativas de custo das travessias rodoviárias. Todavia, a obtenção de uma fórmula de cálculo mais aproximada da realidade, deverá considerar diversos outros aspectos existentes (Drummond, 2008).

Alguns custos fixos que podem ser citados são: o licenciamento, a reposição/renovação de frota e/ ou equipamentos, seguros, remuneração do capital investido, luz, aluguéis, salários e encargos de funcionários (motoristas, oficina, administrativos, vendas, comercial etc.), entre outros. Já os custos variáveis, por exemplo, seriam os valores gastos com a manutenção de veículos, combustíveis, lubrificantes, taxas de pedágio, TAP - Tarifa Adicional de Pedágio, TUV - Tarifa de Utilização da Via, AET - Autorização Especial de Trânsito etc. Representam outros custos a parte de gerenciamento de riscos, restrições ao trânsito, cursos obrigatórios etc. (Dominici, 2017). 
Dessa forma, a partir do conhecimento dos principais custos envolvidos com a operação de transporte, a organização poderá administrar, precificar adequadamente seus serviços, agregar valor ao seu negócio e ser competitiva no nicho de mercado que atuar.

\section{Financiamento Rodoviário}

Para que novas rodovias sejam construídas e toda a infraestrutura existente seja mantida, é necessária uma fonte sustentável e confiável de financiamento. Grande parte dos investimentos destinados a infraestrutura de transportes origina-se dos orçamentos nacionais (Riani, 2013) e a outra parte, por meio da exploração privada.

O road pricing é um método de arrecadação de recursos para financiar a construção, manutenção e adequações das instalações de uma rodovia. Os principais objetivos da cobrança pelo uso da via (pedágio/ TAP/ TUV) são: obter receita, promover a eficiência na alocação de recursos, reduzir o tráfego e seus efeitos negativos (Senna e Michel, 2006).

Além das taxas e tarifas correspondentes ao uso da via existem outros custos que são pagos diretamente pelos motoristas como: tempo gasto, manutenção do veículo, combustível etc. Com relação as rodovias, especificamente, os custos referem-se aos danos no pavimento, acidentes, congestionamentos e poluição ambiental, uma vez que o uso de veículos produz diversos efeitos colaterais que afetam o meio ambiente como por exemplo: as emissões de $\mathrm{CO}, \mathrm{NF}, \mathrm{NO}_{2}$ e CFC; ruídos e vibrações, poluições da água e efeitos no uso do solo (Senna e Michel, 2006).

Senna e Michel (2006) afirmam que os veículos pesados são os responsáveis pela danificação das rodovias e este entendimento é ratificado pelo FHWA (2017). Nos Estados Unidos, a compreensão é de que existem dois aspectos do peso do caminhão que são interdependentes e que interagem com a infraestrutura rodoviária diretamente: a tara (GVW - Gross Vehicle Mass) e o peso por eixo (axle weight when loading) (FHWA, 2017), o que implicaria no desgaste do pavimento e o preço cobrado pelo uso da via (road princing).

\section{Destinação dos Impostos}

A arrecadação tributária é o sistema de financiamento básico do setor público, que estatisticamente apresenta uma elevada carga de tributos indiretos. Isto ocorre em função da complexidade do sistema tributário brasileiro, da própria estrutura do país e do aparato jurídico-legal que proporciona evasão significativa de tributos pelas camadas mais abastadas e o grande capital.

O Brasil é um país com elevado fluxo de receitas tributárias. Entretanto, 30\% da arrecadação é destinada ao pagamento de encargos das dívidas, cujo percentual equivale, estimativamente, a 4,5 orçamentos anuais do estado de Minas Gerais. Além disso, seu valor é habilmente aumentado pela variação cambial ou a prática de políticas de altas taxas de juros que, acabam por resultar no deslocamento de recursos que poderiam ser aplicados em outras áreas do governo como: saúde, educação, segurança, transporte, saneamento, habitação, etc. (Riani, 2013).

Constitucionalmente a redistribuição dos recursos tributários entre as esferas governamentais ocorrem a partir de critérios básicos. Além destes, outros recursos são disponibilizados por meio de negociação em cada nível do governo, neste caso, não havendo nenhuma obrigatoriedade de repasse. A distribuição hoje do que "sobra", ou seja, a carga tributária líquida - cerca de 70\%, está em torno de 58\% para a União, 25\% Estados e 17\% Municípios (Riani, 2013). 
Consta na Constituição Federal de 1988, em seu artigo 145, que os entes federativos podem instituir impostos, taxas e contribuições de melhorias conforme sua jurisdição. Um imposto é o tributo cuja obrigação tem por fato gerador uma situação independente de qualquer atividade estatal específica, relativa ao contribuinte (Maneira, 2017). As taxas, em razão do exercício do poder de polícia ou pela utilização, efetiva ou potencial, de serviços públicos específicos e divisíveis, prestados ao contribuinte ou postos a sua disposição. A contribuição de melhoria está relacionada a obras públicas (Brasil, 1988).

Neste sentido, os tributos podem ser resumidos entre "vinculados" e "não-vinculados". Sendo que o primeiro se refere aqueles cuja hipótese de incidência consiste numa atuação estatal e o segundo aqueles cuja hipótese é um fato de relevância econômica desvinculado de qualquer atuação do Estado (Maneira, 2017).

\section{Taxas e Tarifas dos Transportes}

O transporte de cargas indivisíveis e/ ou excedentes, ou seja, que ultrapassam as dimensões e pesos constantes na legislação em vigor, vincula-se ao pagamento de taxas com funções diversas. Sendo assim, abaixo consta a relação atualmente praticada pelo setor, variando de acordo com a carga e seu peso, dimensão, rodovias do percurso e ações necessárias para a realização da travessia (DNIT, 2016):

》 Taxa de Autorização Especial de Trânsito (AET);

" Escolta Polícia Rodoviária Federal e Privada;

» Tarifa de Acompanhamento de Travessia por Concessionária de Rodovias;

» Tarifas para remoção e elevação de interferências (concessionárias da rede elétrica e de telefonia);

" Tarifas para remoção e elevação de interferências de placas de sinalização;

» Tarifas para remoção ou deslocamento de "braços" semafóricos);

" Taxa para remoção ou deslocamento de cabines de pedágio;

» Pedágio;

» TAP - Tarifa Adicional de Pedágio que, de acordo com Constantino (2016), onera demasiadamente os produtos oriundos do setor de máquinas e equipamentos, por exemplo. Em sua simulação inferiu, inclusive, que parte das vantagens locacionais disponibilizadas na região do seu estudo por ter comprometimento em razão dessa cobrança;

» TUV - Tarifa de Utilização da Via

Como pôde ser observado no decorrer do estudo, a travessia de uma carga especial é burocraticamente complexa, operacionalmente delicada, detalhada e caríssima. A situação ainda se torna mais desconfortável quando observada a infraestrutura viária, hoje direcionada em parte a iniciativa privada, cujos contratos de concessão são despadronizados e apresentam singularidades que resultam em uma quantidade enorme de problemas e particularidades imprevisíveis para os operadores desta atividade.

De acordo com Senna e Michel (2006) conforme afirmativa que os veículos pesados são os que mais danificam a via e os veículos leves possuem impacto de praticamente zero (Senna e Michel, 2006), a máxima inferida por outro autor é ratificada quando afirma haver falta de transparência no cálculo das tarifas de pedágio, mecanismo principal de financiamento adotado pelo Brasil (Schmitz, 2001).

Considerando-se ainda que as tarifas, conforme a Constituição Federal, estão vinculadas ao seu fim, a reforma tributária proposta na PEC 31, atualmente em aberto, deveria ocupar-se de, além de unificar as formas de arrecadação de impostos, estabelecer 
os vínculos entre cobrança, finalidade e esfera governamental, o que promoveria uma gestão mais eficiente dos recursos públicos e investimentos na infraestrutura de transporte.

\section{Percepção da Qualidade}

Considerando o transporte de cargas especiais como um processo complexo, que de fato o é, torna-se perceptível que sua realização esteja vinculada naturalmente a um conjunto de fatores suscetíveis a problemas, ou seja, resultados indesejáveis que devem ser mitigados ao longo do tempo.

Norteado pela metodologia de gerenciamento da qualidade em processo, conhecido por "Total Quality Control - TQC", compreende-se que a prestação de um serviço é um sistema gerencial que se inicia no ato do reconhecimento das necessidades das pessoas (custo, escopo, tempo, segurança, etc.) para posterior estabelecimento de padrões de atendimento e manutenção dos padrões de qualidade, a partir de uma abordagem humanista (Campos, 2004).

No estudo ora realizado, os embarcadores das cargas, foram vistos como o principal "capital" do sistema e da sociedade, representada pelo governo. A empresa prestadora do serviço de transporte depende dos embarcadores, que fornecem resultados financeiros para pagamento de pessoal e ressarcimento do investimento realizado. Os embarcadores são, também, "capital" para os governantes, uma vez que no preço das mercadorias transportadas estão "inclusos": o emprego, a remuneração dos trabalhadores das empresas de transportes e os impostos para investimentos governamentais.

\section{Metodologia do estudo}

Considerando-se que as práticas e custos do transporte de cargas especiais em rodovias foram exploradas por meio de pesquisa bibliográfica, o instrumento de avaliação teve por objetivo reconhecer a percepção dos entraves do processo de travessia deste tipo de carga, cuja resultante estaria relacionada diretamente ao impacto do tempo e custo para as empresas do ramo.

O instrumento de avaliação e medida eletrônico, selecionado por permitir maior alcance territorial, foi dividido em seis fatores utilizando-se a escala Likert em conjunto a análise fatorial para dados ordinais. Tal escala é apropriada a obtenção de resultados quantitativos nas pesquisas de opinião (Wanke, 2010), ou seja, a quantificação do perfil das empresas respondentes e da percepção da influência da qualidade das rodovias ao transporte de cargas.

Ainda sobre a escala optou-se pela divisão em 5 (cinco) categorias sendo: a pontuação mais próxima de 1 (um) de maior importância e mais próxima de 5 (cinco) de menor importância. No que diz respeito a análise da percepção de valores financeiros cobrados, a legenda foi adaptada, dividindo-se também em 5 (cinco) categorias sendo: a pontuação mais próxima de 1 (um) considerada muito cara e mais próxima de 5 (cinco) muito barata.

A possibilidade desta análise, considerando fatores subjetivos como a experiência e percepção de empresas do ramo, permitiu trazer à tona os entraves do processo de transporte de cargas especiais para o meio acadêmico através de 63 perguntas.

Para facilitar a compreensão e otimizar os resultados, as questões foram agrupadas em 6 (seis) domínios, cuja intencionalidade é apresentada no Quadro 1: 
Quadro 1. Objetivos x Domínio. Fonte: Elaboração Própria

\begin{tabular}{|l|l|}
\hline Domínio & Intuito da Análise \\
\hline Rotas & Identificar fatores de influência na escolha. \\
\hline Tarifas & Classificar o valor conforme percepção. \\
\hline Pavimentação & $\begin{array}{l}\text { Identificar as relações e como as condições da } \\
\text { rodovia podem influenciar no tempo e custo da } \\
\text { travessia. }\end{array}$ \\
\cline { 1 - 1 } Sinalização e Dispositivos auxiliares & \\
\hline Geometria da via &
\end{tabular}

A investigação partiu do universo de transportadoras de cargas usuárias do modal rodoviário obtido a partir do relatório de Registro Nacional de Transportadores Rodoviários de Cargas (RNTRC) do último ano disponível, neste caso, 2016. Para a pesquisa seriam válidas somente as transportadoras ou empresas conhecedoras do processo de travessia rodoviária de cargas especiais, indivisíveis ou não, excedentes em peso e/ ou dimensão.

Em função dos obstáculos encontrados, situação recorrente em inúmeros estudos no Brasil (Paes, 2009), optou-se por um estudo sem necessariamente realizar um cálculo amostral teórico, dada a indisponibilidade de dados oficiais extensivos e confiáveis para este feito.

Considerando-se uma ligação intrínseca própria do ramo de transporte rodoviário, utilizou-se a técnica metodológica da amostra em bola de neve (snowball sampling). O método que partiu de uma mala direta enviada por e-mail a 5 empresas em 02-042018 às 14:34h, então consideradas sementes da amostra, alcançou até 30-05-2018 um total de 67 empresas em consequência da divulgação da pesquisa entre empresas do ramo. Além disso foram realizados contatos telefônicos para reforçar a importância do estudo, totalizando 20 empresas participantes efetivas da pesquisa.

Por fim, considerando-se a amostra real obtida, foi constituído um conjunto de parâmetros para a análise dos diferentes aspectos que constituem o conceito de qualidade das rodovias, bem como analisadas estatisticamente as amostras a partir do teste de ANOVA, Teste Kolmogorov-Smirnov para a normalidade dos dados, Alfa de Cronbach, Análise Fatorial, Teste de Igualdade de Duas Proporções, Correlação de Pearson, Intervalo de Confiança para a Média e o P-valor.

\section{Tratamento e análise de dados}

Para mapear os fatores de influência ao escolher uma rota de transporte, os respondentes avaliaram, segundo sua percepção, o que era de maior ou menor importância em sua decisão. Visando notar como os valores cobrados eram percebidos, foi solicitado que classificassem algumas taxas e tarifas obrigatórias, baseando-se na legenda graduada entre muito cara e muito barata.

Diante da possibilidade da afetividade no tempo e custo final dos transportes, ocasionadas por restrições de tráfego, por exemplo, aspectos físicos das rodovias foram julgados pelos respondentes como: a pavimentação, sinalização e dispositivos auxiliares, baseando-se na detecção de sua existência, ausência e estado de conservação ou legibilidade, como no caso das placas informativas.

Já a geometria da via foi avaliada quanto a percepção da importância da capacidade portante estrutural, tipo de perfil, pistas, faixas, ausência ou presença de acostamentos e estado de conservação em geral. Em função de algumas questões não se enquadrarem 
categoricamente nos grupos de perguntas anteriores, o domínio designado como "aspectos adicionais" avaliou fatores que, hipoteticamente, podem interferir no processo de transporte de cargas especiais como por exemplo: a presença ou ausência de serviços de apoio, conciliação entre instituições para escolta e outros.

Como resultado das questões anteriores, as médias atribuídas pelas empresas são apresentadas na figura 1 . Observe que as notas obtidas, corroboraram a ideia do quanto os fatores abordados nesta pesquisa, são relevantes ou muito importantes quando envolvem a tomada de decisão de uma rota e os possíveis fatores que causam impacto no tempo e aumento de custo no processo de travessia das cargas especiais:

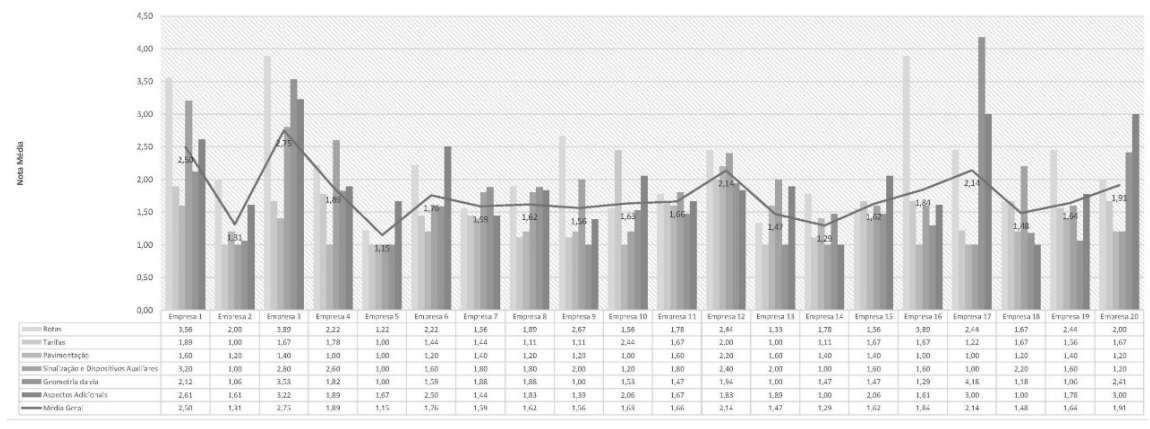

Figura 1. Resultado das Notas das Empresa por Domínio. Fonte: Elaboração Própria

Para este trabalho, foi definido um nível de significância de 0,05 (5\%) e todos os intervalos de confiança construídos ao longo do trabalho com 95\%. Utilizaram-se testes estatísticos paramétricos a partir dos testes da normalidade das variáveis quantitativas de desfecho principal através do teste de Kolmogorov-Smirnov (KS) e concluiu-se haver normalidade conforme Quadro 2:

Quadro 2. Teste K-S. Fonte: Elaboração própria.

\begin{tabular}{ll}
\hline P-valor & \\
\hline Rotas & 0,516 \\
\hline Tarifas & 0,651 \\
\hline Pavimentação & 0,426 \\
\hline Sinalização e Dispositivos Auxiliares & 0,882 \\
\hline Geometria da via & 0,358 \\
\hline Aspectos Adicionais & 0,465 \\
\hline
\end{tabular}

O estudo iniciou-se a partir da análise que mede a consistência interna do protocolo pela técnica de Alfa de Cronbach apresentada no Quadro 3 para averiguação das questões de cada domínio.

Quadro 3. Alfa de Cronbach por Domínio. Fonte: Elaboração própria.

\begin{tabular}{ll}
\hline Alfa & \\
\hline Rotas & 0,869 \\
\hline Tarifas & 0,793 \\
\hline Pavimentação & 0,665 \\
\hline Sinalização e Dispositivos auxiliares & 0,840 \\
\hline Geometria da via & 0,966 \\
\hline Aspectos Adicionais & 0,933 \\
\hline Todos & 0,957 \\
\hline
\end{tabular}


Tem-se que os valores dos domínios são altos. O menor deles ocorreu para "Pavimentação" com 0,665 , mas que se considere um valor bom. No total do protocolo tem-se um Alfa de 0,957, o que é excelente. Assim, concluiu-se que o protocolo é consistente.

Utilizou-se a mesma técnica do Alfa de Cronbach para medição da consistência do protocolo total, mas desta vez, retirando-se uma questão por vez. Nesta etapa, concluiuse a inexistência de questão prejudicial ao protocolo, pois todos os Alfas calculados, tiveram seus valores praticamente idênticos aos valores com todas as 63 questões, de 0,957 mostrado no Quadro 3.

Com o objetivo de criar fatores, ou seja, agrupar algumas questões cujo significado seja comum, foi feita análise fatorial a partir do método de rotação ortogonal Varimax com normalização "Kaiser". Neste método, são considerados os eigenvalues (valores próprios) maior que 1,0 .

Os fatores com valores próprios (eigenvalues) maiores do que 1 foram obtidos pelo método de Componentes Principais da análise fatorial 1. Para cada fator, apresentase a variabilidade explicada por este fator e a variabilidade acumulada no quadro 4 .

Quadro 4. Valores Próprios e Variabilidade dos Fatores. Fonte: Elaboração própria.

\begin{tabular}{|l|c|c|c|}
\hline & Eigenvalues & \% Variância & \% Acumulado \\
\hline Fator 1 & 20,895 & $33,20 \%$ & $33,20 \%$ \\
\hline Fator 2 & 7,856 & $12,50 \%$ & $45,60 \%$ \\
\hline Fator 3 & 5,777 & $9,20 \%$ & $54,80 \%$ \\
\hline Fator 4 & 4,265 & $6,80 \%$ & $61,60 \%$ \\
\hline Fator 5 & 3,591 & $5,70 \%$ & $67,30 \%$ \\
\hline Fator 6 & 3,216 & $5,10 \%$ & $72,40 \%$ \\
\hline Fator 7 & 3,082 & $4,90 \%$ & $77,30 \%$ \\
\hline Fator 8 & 2,944 & $4,70 \%$ & $81,90 \%$ \\
\hline Fator 9 & 2,517 & $4,00 \%$ & $85,90 \%$ \\
\hline Fator 10 & 2,042 & $3,20 \%$ & $89,20 \%$ \\
\hline Fator 11 & 1,355 & $2,20 \%$ & $91,30 \%$ \\
\hline Fator 12 & 1,156 & $1,80 \%$ & $93,20 \%$ \\
\hline
\end{tabular}

Observou-se que 63 questões geraram 12 fatores (grupos de questões), onde a variabilidade total explicada por estes 12 fatores resultou em 93,2\% (do total de 100\%), o que pode ser considerado um valor excelente. A seguir, no quadro 5, é apresentada a composição de cada fator e seu contexto. 
Quadro 5. Temas por Domínios e Fatores

\begin{tabular}{|c|c|c|}
\hline Fatores & Domínios & Contexto das Questões \\
\hline \multirow{5}{*}{ Fator 1} & Tarifas & TUV - Tarifa de Utilização da Via. \\
\hline & & Limitação da capacidade portante de viadutos e pontes. \\
\hline & Geometria da via & $\begin{array}{l}\text { Inexistência de acostamento, más condições, destruído, sem pavimento; Tipo } \\
\text { de perfil - ondulado ou montanhoso; Característica: Pista dupla com canteiro } \\
\text { central; pista dupla com barreira central; pista dupla com faixa central, pista } \\
\text { simples de mão única; pista simples de mão dupla; Ausência, más condições } \\
\text { ou destruição das faixas adicionais de subida; Ausência de defensas ou placas } \\
\text { informativas sobre curvas perigosas. }\end{array}$ \\
\hline & \multirow[t]{2}{*}{ Aspectos Adicionais } & $\begin{array}{l}\text { Ocorrência de desvio, restrição total ou parcial do tráfego por queda de barreira, } \\
\text { ponte caída, erosão na pista, buraco grande, obstáculos, alagamentos, obras. } \\
\text { Ausência de Postos de abastecimento em longas distâncias; Inexistência de } \\
\text { pátio para estacionamento dos veículos ou conjuntos transportadores; O Baixo } \\
\text { desenvolvimento industrial para a criação de veículos especiais; A Falta de } \\
\text { transparência na divulgação dos procedimentos legais do transporte de cargas } \\
\text { dessa natureza. }\end{array}$ \\
\hline & & $\begin{array}{l}\text { Ausência de Postos de abastecimento em longas distâncias; Inexistência de pátio } \\
\text { para estacionamento. Baixo desenvolvimento industrial de veículos especiais; } \\
\text { Divulgação insuficiente dos procedimentos legais do transporte de cargas } \\
\text { especiais. }\end{array}$ \\
\hline \multirow[t]{2}{*}{ Fator 2} & Rotas & $\begin{array}{l}\text { Tipo de relevo - Plano, ondulado ou montanhoso; Largura das faixas de } \\
\text { rolamento e acostamentos externos; Restrições de gabaritos verticais e } \\
\text { horizontais; Capacidade portante das pontes e viadutos; Raio de curvatura e } \\
\text { inclinação da pista; Estado de conservação ou tipo de pavimentação. }\end{array}$ \\
\hline & Aspectos Adicionais & $\begin{array}{l}\text { Falta de Segurança Pública e despadronização da arquitetura das praças de } \\
\text { pedágio. }\end{array}$ \\
\hline \multirow{3}{*}{ Fator 3} & Tarifas & Taxa de Autorização Especial de Trânsito (AET) e pedágios. \\
\hline & $\begin{array}{l}\text { Sinalização e Dispositivos } \\
\text { Auxiliares }\end{array}$ & $\begin{array}{l}\text { Desgaste, visibilidade em função do posicionamento, inexistência ou ilegibilidade } \\
\text { de placas de sinalização e ausência de defensas. }\end{array}$ \\
\hline & Geometria da via & Ausência de defensas em pontes ou viadutos sem acostamento. \\
\hline Fator 4 & Aspectos Adicionais & $\begin{array}{l}\text { Conciliação entre escoltas Credenciadas e Polícia Rodoviária Federal; } \\
\text { Obrigatoriedade da programação de tráfego junto as concessionárias das } \\
\text { rodovias; prazo legal fornecido para a pesagem do veículo ou conjunto de } \\
\text { veículos; falta de mão de obra operacional especializada. }\end{array}$ \\
\hline Fator 5 & Tarifas & $\begin{array}{l}\text { Tarifas para remoção ou deslocamento de interferências de concessionárias da } \\
\text { serviços essenciais, placas de sinalização, braços semafóricos ou cabines de } \\
\text { pedágio. }\end{array}$ \\
\hline \multirow{2}{*}{ Fator 6} & Tarifas & TAP - Tarifa Adicional de Pedágio. \\
\hline & Aspectos Adicionais & $\begin{array}{l}\text { Localização dos Postos da Polícia Rodoviária Federal ou Estadual; Postos do } \\
\text { Corpo de Bombeiros e balanças de pesagem. }\end{array}$ \\
\hline \multirow{2}{*}{ Fator 7} & Pavimentação & $\begin{array}{l}\text { Ausência e grau de destruição do pavimento e redução da velocidade ocasionada } \\
\text { pelas condições da superfície do pavimento. }\end{array}$ \\
\hline & $\begin{array}{l}\text { Sinalização e Dispositivos } \\
\text { Auxiliares }\end{array}$ & Restrição do gabarito vertical e/ou horizontal \\
\hline \multirow[b]{2}{*}{ Fator 8} & Pavimentação & Possuem trincas em malha ou remendos no pavimento \\
\hline & Aspectos Adicionais & $\begin{array}{l}\text { Inexistência de Borracharias, concessionárias ou oficinas mecânicas } \\
\text { especializadas e ausência de restaurantes e lanchonetes em longas distâncias }\end{array}$ \\
\hline \multirow{2}{*}{ Fator 9} & Pavimentação & Presença de afundamento, ondulação ou buraco. \\
\hline & Geometria da via & Tipo de Perfil - Plano \\
\hline Fator 10 & Rotas & Localização dos postos de fiscalização e praças de pedágio. \\
\hline Fator 11 & Tarifas & Tarifa de Acompanhamento de Travessia por Concessionária de Rodovias \\
\hline Fator 12 & Rotas & Tipo de gestão da rodovia (pública ou privada) \\
\hline
\end{tabular}


Ainda na análise fatorial, foram analisadas as cargas fatoriais para cada uma das questões em cada um dos fatores. Entende-se que quanto maior for a carga, mais a questão é representativa para o fator. Sendo assim, os resultados obtidos nesta etapa convergiram em 38 interações, uma quantidade mediana, mostrando certa complexidade para criar os fatores. Como exemplo do resultado do principal fator, ou seja, o fator 1 que detém sozinho $33,2 \%$ da variabilidade dos dados, é composto pela maior quantidade de questões, ou seja, 22 questões. A principal questão desse Fator 1, com carga fatorial de 0,943, relaciona-se às rodovias que possuem curvas perigosas sem placas e/ou sem defensas.

Após a definição dos domínios deste estudo, foram calculados os escores, que correspondem à média das questões de cada domínio. Para tanto, foi realizada uma análise descritiva completa para estes escores e a descrição do "tempo de atuação das empresas" expressa em anos conforme Quadro 6.

Quadro 6. Descritiva Completa dos Escores dos Domínios dos Protocolos. Fonte: Elaboração própria.

\begin{tabular}{|l|c|c|c|c|c|c|c|c|c|c|}
\hline Descritiva & Média & Mediana & $\begin{array}{c}\text { Desvio } \\
\text { Padrão }\end{array}$ & CV & Q1 & Q3 & Min & Max & N & IC \\
\hline $\begin{array}{l}\text { Tempo de Atuação } \\
\text { da Empresa }\end{array}$ & 27,9 & 16,5 & 21,9 & $78 \%$ & 12,8 & 38,8 & 6 & 80 & 20 & 9,6 \\
\hline Rotas & 2,21 & 2 & 0,79 & $36 \%$ & 1,64 & 2,44 & 1,22 & 3,89 & 20 & 0,34 \\
\hline Tarifas & 1,51 & 1,61 & 0,39 & $26 \%$ & 1,11 & 1,67 & 1 & 2,44 & 20 & 0,17 \\
\hline Pavimentação & 1,31 & 1,2 & 0,29 & $22 \%$ & 1,15 & 1,4 & 1 & 2,2 & 20 & 0,13 \\
\hline $\begin{array}{l}\text { Sinalização e } \\
\text { Dispositivos } \\
\text { auxiliares }\end{array}$ & 1,77 & 1,7 & 0,63 & $36 \%$ & 1,2 & 2,05 & 1 & 3,2 & 20 & 0,28 \\
\hline Geometria da via & 1,74 & 1,5 & 0,83 & $48 \%$ & 1,15 & 1,9 & 1 & 4,18 & 20 & 0,37 \\
\hline Aspectos Adicionais & 1,95 & 1,83 & 0,62 & $32 \%$ & 1,61 & 2,17 & 1 & 3,22 & 20 & 0,27 \\
\hline
\end{tabular}

Foi verificado que os domínios do protocolo possuem baixa variabilidade, isso porque o Coeficiente de variação (CV) é menor que $50 \%$, o que é bom, pois demonstra que os dados são homogêneos. Como exemplo tem-se a média do domínio de "Rotas" com o valor de $2,21 \pm 0,34$. Assim, neste domínio, quanto mais próximo de 1 , mais importante ele se torna.

Outro exemplo pode ser o domínio de "Tarifas" com média de 1,51 $\pm 0,17$. Neste domínio, quanto mais próximo de 1, mais clara é a informação. Desse modo, concluise que a percepção dos respondentes a respeito da qualidade na prestação de serviços relacionadas ao uso das rodovias, em geral são consideradas muito caras.

Já o domínio "Pavimentação", cuja média foi de 1,31 \pm 0,13, entende-se que o estado de conservação do revestimento da rodovia é muito importante e capaz de interferir negativamente no tempo e custos operacionais do transporte.

A sinalização nas rodovias visa o ordenamento do fluxo de veículos e pedestres, auxilia no controle e orientação de diversas situações como problemas de geometria da via, obstáculos, topografia etc. Já a geometria da via relaciona-se ao tipo, perfil, faixas adicionais de subidas, pontes, viadutos, curvas perigosas e acostamentos das rodovias.

Tanto o domínio "Sinalização e Dispositivos", quanto "Geometria da Via" e "Aspectos Adicionais", com médias 1,77 $\pm 0,28,1,74 \pm 0,37$ e 1,95 $\pm 0,27$ respectivamente, foram considerados importantes e capazes de interferirem negativamente nos resultados do processo de travessia em relação ao custo e tempo. 
Para a caracterização da distribuição da frequência relativa (percentuais) das variáveis qualitativas do Perfil, utilizou-se o teste de Igualdade de Duas Proporções e calcularamse os percentuais para o total de 20 sujeitos (sempre). A análise foi realizada conforme legenda a seguir:

" p-valores $(* * *)$ : considerados estatisticamente significativos perante o nível de significância adotado;

》 p-valores $\left({ }^{\mathrm{xxx}}\right)$ : que por estarem próximos do limite de aceitação, são considerados que tendem a ser significativos (até 5 pontos percentuais acima do valor do alfa adotado);

» p-valores (sem marcações): considerados não significativos perante o nível de significância adotado.

Já nas variáveis com 3 ou mais níveis de resposta, foi mostrada na última coluna os p-valores da comparação de cada nível de resposta sempre em relação ao mais prevalente que está como Referência (Ref.).

De acordo com as Quadros 7 e 8, tem-se que o tipo de empresa mais prevalente foi "ECT" com $65,0 \%$ e o porte da maioria é média, representada por $60 \%$ do total. Enquanto o tipo de empresa é estatisticamente significante em relação as demais, o porte médio não apresenta diferença estatística significante em relação ao porte pequeno ( $\mathrm{p}$-valor $=0,057$ ).

Quadro 7. Distribuição de “Tipo de Empresa”. Fonte: Elaboração própria.

\begin{tabular}{|l|c|c|c|}
\hline Tipo de Empresa & N & $\%$ & P-valor \\
\hline Empresa de Transporte Rodoviário de Cargas - ETC & 13 & $65,00 \%$ & Ref. \\
\hline Operador Logístico & 4 & $20,00 \%$ & $0,004^{* * *}$ \\
\hline Outros & 3 & $15,00 \%$ & $0,001^{* * *}$ \\
\hline
\end{tabular}

Quadro 8. Distribuição de "Porte da Empresa”. Fonte: Elaboração própria.

\begin{tabular}{|l|c|c|c|}
\hline Porte da Empresa & N & $\%$ & P-valor \\
\hline Grande & 2 & $10,00 \%$ & $<0,001^{* * *}$ \\
\hline Média & 12 & $60,00 \%$ & Ref. \\
\hline Pequena & 6 & $30,00 \%$ & $0,057^{x \times x}$ \\
\hline
\end{tabular}

Com $50 \%$ da distância média das travessias das empresas superiores a $1.000 \mathrm{~km}$, tem-se que $85 \%$ das empresas utilizam as rodovias mais que 13 vezes, ou seja, são estatisticamente significantes em sua maioria (exceção distância média de $251 \mathrm{~km}$ a $500 \mathrm{~km}$ ) e portanto sugere-se considerável experiência de campo para opinar nesta pesquisa (Quadros 9 e 10).

Quadro 9. Distribuição de "Frequência de Utilização das Rodovias". Fonte: Elaboração própria.

\begin{tabular}{|l|c|c|c|}
\hline Frequência de Utilização das Rodovias & N & $\%$ & P-valor \\
\hline 2 a 5 vezes & 2 & $10,00 \%$ & $<0,001^{* * *}$ \\
\hline 10 a 13 vezes & 1 & $5,00 \%$ & $<0,001^{* * *}$ \\
\hline Mais de 13 vezes & 17 & $85,00 \%$ & Ref. \\
\hline
\end{tabular}

Quadro 10. Distribuição de “Distância Média das Travessias da Empresa”. Fonte: Elaboração própria.

\begin{tabular}{|l|c|c|c|}
\hline Distância Média das Travessias da Empresa & N & $\%$ & P-valor \\
\hline Menos que $250 \mathrm{Km}$ & 3 & $15,00 \%$ & $0,018^{* * *}$ \\
\hline $251 \mathrm{Km}$ a $500 \mathrm{Km}$ & 5 & $25,00 \%$ & 0,102 \\
\hline $501 \mathrm{Km}$ a $750 \mathrm{Km}$ & 2 & $10,00 \%$ & $0,006^{* * *}$ \\
\hline Mais de $1000 \mathrm{Km}$ & 10 & $50,00 \%$ & Ref. \\
\hline
\end{tabular}


Estudo com maior concentração na região sudeste do Brasil, com 75\% em relação as demais regiões, sendo 45\% de empresas sediadas no Estado de São Paulo.

Na distribuição de "Preferência por Gestão Rodoviária" (Quadro 11), tem-se 65,0\% para a gestão privada contra 35,0\% para pública, mas essa não é uma diferença estatisticamente significante $(\mathrm{p}$-valor $=0,058)$.

Quadro 11. Distribuição de "Preferência por Gestão Rodoviária”. Fonte: Elaboração própria.

\begin{tabular}{|l|c|c|c|}
\hline Preferência por Tipo de Gestão Rodoviária & N & $\%$ & P-valor \\
\hline Privada & 13 & $65,00 \%$ & \multirow{2}{*}{0,058 xxx } \\
\cline { 1 - 2 } Pública & 7 & $35,00 \%$ & \\
\hline
\end{tabular}

A partir das notas individuais atribuídas às variáveis, foi elaborada a matriz do Quadro 12. A Correlação de Pearson visa a identificação do grau de correlação entre os escores dos domínios do protocolo conforme demonstrado a seguir:

Quadro 12. Correlação dos Domínios do Protocolo. Fonte: Elaboração própria.

\begin{tabular}{|c|c|c|c|c|c|c|}
\hline & & Rotas & Tarifas & Pavimentação & $\begin{array}{c}\text { Sinalização e } \\
\text { Dispositivos } \\
\text { auxiliares }\end{array}$ & $\begin{array}{c}\text { Geometria } \\
\text { da via }\end{array}$ \\
\hline$T \cdot T^{-1}$ & Correlação (r) & $24,90 \%$ & & & & \\
\hline & P-valor & 0,29 & & & & \\
\hline Daumpon & Correlação (r) & $5,40 \%$ & $17,60 \%$ & & & \\
\hline avint & P-valor & 0,822 & 0,458 & & & \\
\hline Sinalização e & Correlação (r) & $50,80 \%$ & $37,40 \%$ & $44,90 \%$ & & \\
\hline auxiliares & P-valor & $0,022 * * *$ & 0,105 & $0,047^{* * *}$ & & \\
\hline Geometria & Correlação (r) & $40,00 \%$ & $15,10 \%$ & $-3,10 \%$ & $14,20 \%$ & \\
\hline da via & P-valor & $0,081 x x x$ & 0,525 & 0,898 & 0,551 & \\
\hline Aspectos & Correlação (r) & $41,10 \%$ & $24,00 \%$ & $-4,20 \%$ & $16,80 \%$ & $76,50 \%$ \\
\hline Adicionais & P-valor & $0,072^{x x x}$ & 0,308 & 0,862 & 0,479 & $<0,001 * * *$ \\
\hline
\end{tabular}

Apesar da correlação ser um valor que varia de -1 a 1, para facilitar o entendimento, os valores foram transformados em porcentagem, forma válida e utilizada para representar um número absoluto.

Foram encontradas três correlações estatisticamente significantes, ou seja, diferentes de zero. A maior delas ocorreu entre "Geometria da via" e "Aspectos Adicionais" com valor de 76,5\%. Esse valor por ser positivo mostra que quanto maior o escore de "Geometria da via" maior também será o escore de "Aspectos Adicionais". Em outras palavras, quanto mais importante for a geometria da via, mais importante serão os aspectos adicionais e vice-versa. Essa é uma correlação classificada como sendo boa.

Ao ponderar p-valores próximos do limite de aceitação nos domínios Rotas, Tarifas, Pavimentação, Sinalização e Dispositivos Auxiliares foram encontradas correlações positivas de classificação "Regular". Com objetivo de identificar alguma influência nos escores, comparações e ajustes foram realizados e questões foram reagrupadas com objetivo de alcançar uma análise fidedigna. 


\section{Considerações Finais}

Também foram medidas as correlações entre as questões do protocolo, gerando-se uma tabela de 63 colunas e 63 linhas. Somada a apreciação de documentos e respostas e considerando $\mathrm{p}$-valores estatisticamente significativos perante o nível de significância adotado, chegaram-se às seguintes análises por domínio:

\section{Para o domínio rotas}

Aspectos como a largura das faixas, a existência de acostamentos externos e o tipo de relevo são determinantes para a seleção de uma rota. A detecção de possíveis restrições de gabaritos verticais e horizontais e os empecilhos decorrentes da falta de capacidade portante das pontes e viadutos, resultarão na investigação inclusive do raio de curvatura da via, além de maior atenção com relação ao estado ou tipo de conservação do pavimento que possam dificultar ainda mais a travessia.

Diante das dificuldades apontadas, o Plano Nacional de Manutenção Rodoviária (PNMR) do DNIT foi consultado e (Hoffmann e Afonso, 2018), em função da priorização dos investimentos estar baseada estritamente em aspectos técnicos e orçamentários, a tomada de decisão do que se entende por "urgente", possivelmente distancia-se das necessidades reais decorrentes da experimentação das vias.

É entendido como fundamental a ênfase estratégica adotada pelo DNIT, entretanto para além dela, é necessário garantir uma priorização vinculada a realidade da vida prática. Sugere-se a partir de então, a inserção de audiências públicas na $1^{\text {a }}$ fase do PNMR de forma sistemática e periódica, permitindo trazer a superfície os incômodos singulares vivenciados pelos operadores e transportadores de cargas especiais no dia a dia, como a grave questão da falta capacidade portante das pontes e viadutos.

\section{Para o domínio tarifas}

Embora possam parecer insignificantes os custos relacionados as tarifas, sob o ponto de vista estatístico, considera-se que a preferência é que se tenha players privados na administração da via, pois tudo que envolve o poder público no Brasil é extremamente burocrático e muitas vezes pode até inviabilizar a completa conformidade com o regramento de regência.

Se sob o ponto de vista estatístico as tarifas parecem insignificantes, ao vincular as taxas para remoção, elevação e deslocamento de interferências na via e adicionais de pedágio diretamente a percepção da qualidade do serviço prestado, torna-se evidente a insatisfação e notoriedade quanto ao alto custo praticado. Fato este ratificado pelas notas médias gerais, que variam de 1 (muito cara) a 2 (cara) por empresa.

\section{Para o domínio Pavimentação}

Concluiu-se, sem qualquer dificuldade, que as condições da superfície do pavimento alteram sobremaneira a avaliação acerca do preço justo cobrado nas tarifas de acompanhamento de travessia por concessionárias de rodovias. Se a superfície não é adequada, o veículo deve reduzir a velocidade e isso impacta diretamente em outros custos, o que desperta severas críticas e inconformismos. Note, $95 \%$ das empresas respondentes consideram o pavimento e o estado de conservação muito importantes.

\section{Para o domínio Sinalização e Dispositivos auxiliares}

A definição da rota é influenciada pela possibilidade das restrições de gabaritos verticais. Isso ganha maior atenção quando se observa a inexistência de sinalização e 
dispositivos auxiliares adequados. Compreende-se que, se constatada a maior influência da ausência de defensas em uma via, maior será a percepção do preço cobrado pela Taxa de Autorização Especial de Trânsito (AET). Além disso, entende-se que quanto maior for o comprometimento da visibilidade em uma rodovia, mais evidente será o problema das placas ilegíveis e inexistentes, consequentemente, falta de segurança ao trafegar na mesma.

O setor ainda apresenta queixas a respeito do agravamento do risco de acidentes por conta de ausência de manutenção mínima em placas e bordas da via. Muitas vezes se depara com placas escondidas atrás da vegetação, que é uma manutenção cujos custos não são altos, observados os custos de equipamentos para esta finalidade e a quantidade de funcionários para realizar o serviço.

\section{Para o domínio Geometria da Via}

É considerada proporcional a importância dos acostamentos inexistentes, sem pavimento ou destruídos e a ausência de defensas nas pontes quanto a sua influência nos custos e tempo de travessia de cargas especiais. Isto porque se a via estiver com quaisquer problemas no acostamento, provavelmente as pontes e viadutos estarão em condições semelhantes.

Em geral, a percepção das condições do pavimento e inexistência de acostamento é mais notada nas rodovias de perfil plano, considerando-se as particularidades de cada tipo de pista. Diferentemente do que ocorre com as vias de perfil ondulado ou montanhoso, que dependendo do tipo de pista também, passam a ter como alvos importantes e preocupantes a existência de pontes e viadutos sem acostamento ou sem defensas.

Se a pista for simples, de mão única ou dupla, maior será a importância do estado de conservação ou tipo de pavimento da rodovia, a ocorrência de problemas de acostamento em más condições e o tipo de perfil. Isto posto que não havendo faixa adicional de subida, possivelmente não haverá acostamento.

Uma vez percebida a relevância da faixa adicional de subida em más condições, maior será a importância da verificação da capacidade portante das pontes e viadutos, o tipo ou estado de conservação do pavimento, presença de acostamentos e defensas, e a percepção negativa dos valores cobrados pela TUV.

Quanto maior for a falta de sinalização ou defensas em curvas perigosas, mais alarmantes serão os problemas ao se utilizarem rodovias de perfil ondulado ou montanhoso sem faixa adicional de subida ou destruídas.

\section{Para o Domínio Aspectos Adicionais}

Neste domínio observou-se que havendo restrição total ou parcial do tráfego por queda de barreira em rodovias de perfil ondulado ou montanhoso, ponte caída, erosão na pista, buraco grande, obstáculos, alagamentos, mais evidente será a ausência de acostamento e maior será a inquietação com a falta de faixa adicional de subida e curva perigosas sem placa de sinalização ou defensas. Considerou-se importante a atual localização dos postos do Corpo de Bombeiros tanto quanto a dos Postos da Polícia Rodoviária Federal ou Estadual.

As obras que ocasionam desvio de tráfego, como por exemplo as realizadas em praças de pedágio, são importantes principalmente quando presentes em rodovias de perfil ondulado ou montanhoso de pista simples, pois ocasionam maior preocupação com a falta de segurança pública. Além disso tornam-se evidentes também a apreensão 
quanto: as restrições de gabaritos verticais e horizontais; a capacidade portante das pontes e viadutos; o tipo ou estado de conservação do pavimento; a falta de faixa adicional de subida ou em más condições; e a sinalização adequada em curvas perigosas.

A ausência de postos de abastecimento em longas distâncias provoca apreensão principalmente quando as rodovias possuem acostamento em más condições e inexistência de faixa adicional de subida, o que independe do tipo de perfil da via.

Onde há carência de concessionárias e oficinas mecânicas de veículos especiais ou conjuntos transportadores, também inexistirão borracharias, problemas de trincas em malha ou remendos no pavimento e oferta de restaurantes ou lanchonetes. Infere-se neste caso, que as rodovias encontrar-se-ão em boas condições, dispensando-se assim, este tipo de cuidados.

A exaltação da deficiência de espaços para estacionamento dos veículos, ou conjuntos transportadores, mostrou-se como problema presente em rodovias cujo perfil é ondulado ou montanhoso, principalmente aquelas sem faixa adicional de subida ou em condições inadequadas e cujas placas de sinalização e defensas em curvas perigosas latentes.

A importância da presente localização das balanças de pesagem é maior ao trafegar em rodovias cujo perfil é plano e em função da atual localização dos Postos da Polícia Rodoviária Federal ou Estadual e dos Postos do Corpo de Bombeiros. Infere-se neste caso maior preocupação com situações fiscalizatórias.

A conciliação entre escoltas credenciadas e Polícia Rodoviária Federal é mais preocupante quando a travessia é realizada em rodovias de perfil ondulado ou montanhoso, quando há presença de obras que ocasionam desvio de tráfego e a inexistência de postos de abastecimento.

Já a obrigatoriedade da programação de tráfego, junto às concessionárias das rodovias, gera maior apreensão em rodovias de perfil plano, aumentando também a importância da presença de postos de abastecimento, concessionárias ou oficinas mecânicas de veículos especiais ou conjuntos transportadores, posicionamento das balanças de pesagem e a conciliação entre escoltas credenciadas e Polícia Rodoviária Federal.

Dependendo do prazo legal fornecido para a pesagem do veículo ou conjunto de veículos, o grau de importância da atual localização das balanças ganha espaço. Além disso, passa a ser inquietante a conciliação entre escoltas credenciadas e Polícia Rodoviária Federal e a obrigatoriedade de programação de tráfego junto às concessionárias das rodovias.

A falta de especialização da mão de obra ganha importância principalmente quando é necessária a programação de tráfego junto as concessionárias das rodovias.

O baixo desenvolvimento industrial para a criação de veículos especiais é evidenciado quando é necessário trafegar em rodovias cujo perfil é ondulado ou montanhoso, e principalmente de pista simples de mão dupla.

É fato que enquanto houver baixa disseminação dos procedimentos legais do transporte de cargas especiais, permanecerão na mesma proporção a existir problemas relativos à limitação da capacidade portante de viadutos e pontes, restrições totais ou parciais de tráfego, ausência de postos de abastecimentos e baixo desenvolvimento industrial para a criação de veículos especiais. 


\section{Conclusão}

A qualidade das rodovias influencia diretamente no tempo de travessia e custo do transporte de cargas especiais. De acordo com a percepção das empresas respondentes, $80 \%$ considera pelo menos importante os fatores abordados na pesquisa.

Embora haja preferência pela gestão privada das rodovias, o valor investido em contrapartida ao serviço prestado foi considerado injusto, principalmente quando fatores relacionados ao estado de conservação, sinalização e geometria da via, obrigam a redução da velocidade do veículo ou conjunto transportador.

As empresas que atuam na logística deste tipo de cargas, necessitam de um mapeamento em tempo real do estado de conservação de rodovias e obras de arte. A disponibilização de um sistema de rotas oficial, contribuiria para o conhecimento prévio de problemas que, muitas vezes, são conhecidos no decorrer das travessias.

É fundamental haver uma adequação das estratégias governamentais de priorização de investimentos, inserindo-se audiências públicas na $1^{\text {a }}$ fase do PNMR. Entende-se que ao estabelecer uma política de cooperação entre as organizações da sociedade civil (operadores e transportadores de cargas especiais) e o DNIT, que as decisões poderão resultar em melhorias objetivas, inclusive fomentando o desenvolvimento industrial brasileiro.

É importante ressaltar que apesar da desvinculação e a destinação dos impostos ser subjetiva, o Estado tem obrigações com a sociedade. As políticas públicas nos moldes atuais, acabam por concorrer entre si, resultando numa prestação de serviços ineficiente em todas as áreas infra estruturais. O que se vê, facilmente, é que o país tem uma infraestrutura deficiente. Dir-se-ia, assim, em linguagem menos formal, que há um pouco de tudo e muito de quase nada.

Esta pesquisa teve como objetivo apresentar a percepção da qualidade das rodovias com o foco de transportadoras de cargas especiais e informações sobre as formas de financiamento rodoviário. Na análise estatística foram utilizados os softwares: SPSS V20, Minitab 16 e Excel Office 2010 cujos resultados obtidos puderam ser apreciados durante a leitura.

Ao longo do estudo, foi possível conhecer a percepção da influência dos custos e condições físicas das rodovias em travessias exclusivamente realizadas por empresas transportadoras e agentes logísticos de cargas especiais. Espera-se que as análises realizadas sirvam de subsídios para futuros estudos pela comunidade acadêmica.

Por fim, viu-se que antes que o governo se empenhe em investimentos em infraestrutura, será necessário que se estude questões de suma importância para a boa gestão e aplicação dos recursos, sob pena de se fazer, por exemplo, excelentes vias para transporte de veículos de passageiros, mas deixando setores também ligados a infraestrutura e desenvolvimento a mingua de bem desempenhar sua missão. Será o caso de adaptar o que se tem hoje, na medida do possível, e quando da realização de novos projetos, que se enxergue além do transporte de passageiros, com uma pista lisa para outros veículos. 


\section{Q Bibliografía}

» Brasil, República Federativa do. (1988). Constituição da República Federativa do Brasil. Publicado em: Presidência da República - Planalto. Recuperado de http://www.planalto.gov.br/ccivil_03/constituicao/constituicao.htm (10/12/2018)

» CNT Conferação Nacional dos Transportes. (2017). Pesquisa CNT de Rodovias 2017: Relatório Gerencial [Livro]. - Brasilia, DF: CNT.

"Campos, V. F. (2004). TQC - Controle da Qualidade Total (no estilo japonês) [Livro]. Vol. 8a Edição. Nova Lima, MG: INDG Tecnologia e Seviços Ltda.

»Constantino, W. (2016). O Preço da Fluidez: Os Pedágios nas Rodovias Paulistas e seus Efeitos sobre a Lucratividade das Empresas do Setor de Máquinas e Equipamentos, Localizadas na Cidade-Região São Paulo. Tese de Doutorado do Programa de Pós-Graduação em Geografia da Universidade de São Paulo.

»DNIT Departamento Nacional de Infra-estrutura de Transportes. (2016). Resolução $n^{\circ}$ 1, de 14 de janeiro de 2016 - Normas para transporte de cargas indivisíveis e excedentes em peso elou dimensões e para o trânsito de veículos especiais em rodovias federais. Recuperado de: (http://www.dnit.gov.br/rodovias/ operacoes-rodoviarias/sistema-de-gerenciamento-de-autorizacao-especialde-transito-siaet/RESOLUO012016DNITCargasIndivisveis.pdf(15/01/2019).

" DNIT Departamento Nacional de Infra-estrutura de Transportes. (2004). Resolução $n^{\circ} 11$ de 19 de outubro de 2004 - Normas de utilização de rodovias federais para transporte de cargas indivisíveis e excedentes em peso elou dimensões para o trânsito de veículos especiais. Brasília, DF. Disponível em: http://www. dnit.gov.br/rodovias/operacoes-rodoviarias/sistema-de-gerenciamento-deautorizacao-especial-de-transito-siaet/copy_of_RESOLUCAO112004DNIT.pdf. (15/01/2019).

»Dominici, J. B. (2017). Gestão do Transporte de Cargas Indivisíveis e do Processo de Obtenção de Autorizações Especiais de Trânsito. São Paulo, SP: Escola de Transportes.

»Drummond, M. A. B. (2008). Uma Contribuição ao Estudo Dos Custos de Transporte Doméstico de Carga no Brasil. Dissertação de Mestrado do Programa de Pós-Graduação em Engenharia de Transportes da Coppe - Instituto Alberto Luiz Coimbra de Pós-Graduação e Pesquisa de Engenharia, da Universidade Federal do Rio de Janeiro.

» FHA Federal Higway Administration U. S. Department of Transportation. (2017). Highway Infrastructure. Recuperado de: (https://www.fhwa.dot.gov/reports/ tswstudy/Vol2-Chapter6.pdf. (08/01/2019).

» Hoffmann, I. C. e Afonso, W. B. (2018). Plano Nacional de Manutenção Rodoviária. Brasília, DF: DNIT

»Maneira, E. (2017). Apontamentos sobre as Espécies Tributárias. Recuperado de: (http://www.maneira.adv.br/imagens/userfiles/files/27.pdf). (11/o1/2019).

» Paes, A. T. (2009). O que fazer quando a distribuição não é normal? Vols. iPt2 3-4. São Paulo, SP: Educ Contin Saúde.

"Riani, F. (2013). Economia do Setor Público - Uma abordagem introdutória. $5^{\text {a }}$ Edição. Rio de Janeiro, RJ: LTC. 
"Schmitz, R. (2001). Uma Contribuição Metodológica para Avaliação de Tarifa de Pedágio em Rodovias. Tese de Doutorado do Programa de Pós Graduação em Engenharia de Produção e Sistemas da Universidade Federal de Santa Catarina.

»Senna, L.A.S. e Michel, F. D. (2006). Rodovias Auto-Sustentadas - O desafio do século XXI. São Paulo, SP: CLA Cultural Ltda.

"Wanke, P. F. (2010). Logística e transporte de cargas no Brasil - produtividade e eficiência no século XXI.1를 Edição. São Paulo, SP: Atlas.

\section{Orlando Celso Longo / orlandolongo@gmail.com}

Doutor em Engenharia de Transportes pela Universidade Federal do Rio de Janeiro (2004), Mestre em Engenharia Civil pela Universidade Federal Fluminense (1987). Atualmente é Professor Titular da Universidade Federal Fluminense. Foi Coordenador do Programa de Pós-graduação em Engenharia Civil da Universidade Federal Fluminense no período 2005 - 2013. Tem experiência na área de Engenharia Civil, com ênfase em Construção Civil, atuando principalmente nos seguintes temas: construção civil, custos, gerenciamento / acompanhamento fiscalização, orçamento, administração de projetos e elaboração e desenvolvimento de projetos de infraestrutura.

\section{Vivian Figueiredo Pereira de Almeida / vivianfa@yahoo.com.br}

Doutoranda em Engenharia Civil pela Universidade Federal Fluminense, Mestre em Engenharia Civil pela Universidade Federal Fluminense. Licenciada em Matemática. Especialista em Educação a Distância. Professora Liberal Universitária (Produção de Disciplinas e Conteúdos para EaD). 